\title{
Teaching Cardiac Surgery: A Major Contemporary Issue in the Academic Institutions
}

\author{
Thierry Carrel ${ }^{1} \quad$ Florian S. Schoenhoff $^{1}$ \\ ${ }^{1}$ Department of Cardiovascular Surgery, University Hospital and \\ University of Bern, Bern, Switzerland \\ Thorac Cardiovasc Surg 2021;69:345-346.
}

The most conventional cardiac procedures, including percutaneous coronary interventions, coronary artery bypass grafting, transcatheter aortic valve implantation, and surgical aortic valve replacement, are among the most often studied procedures in the literature. Primary and secondary end points that are helpful to assess quality of care, relatively easy to define: 30-day mortality and the major cardiovascular adverse events, like myocardial infarction, heart failure, stroke, bleeding requiring reexploration, are among the most important ones.

With this manuscript, the authors present a rather "provocative" paper entitled "Proximalized Total Arch Replacement Can Be Safely Performed by Trainee." 1 While the teachers have to be congratulated for their ability to teach, but also for the excellent results obtained following this particular procedure, there is no doubt that the idea to directly teach residents in aortic arch surgery outside of a dedicated and defined overall training program, requires some comments.

Japanese patients, of course not all, are much more often slender and their chest anatomy is much more comfortable than that encountered in the majority of European or North American patients. Their aortic arch, the first author made this observation several times when visiting Japanese institutions, is quite anterior in the chest and often relatively easily accessible.

I recognize that it is of paramount importance that trainees receive the possibility to learn with experienced attending surgeons how to handle not only the aortic arch but also the aortic root and the ascending aorta in patients presenting with aortic aneurysms and with aortic dissection. In particular, teaching will not only include the purely manual part of the surgery, which may be technically challenging and requires precision, but also all particularities associated with deeper hypothermia, circulatory arrest, and cerebral protection are unforgiving of error.

received

March 26, 2020

accepted after revision

April 29, 2020
Address for correspondence Thierry Carrel, MD, Department of Cardiovascular Surgery, University Hospital and University of Bern, Freiburgstrasse, $\mathrm{CH}-3010$ Bern, Bern, Switzerland (e-mail: thierry.carrel@insel.ch).

Years ago, while discussion on a paper of the IRAD (International Registry of Aortic Dissection) group that reported the results following repair of aortic dissection was ongoing, a well-known aortic expert was claiming that early mortality had not significantly decreased during the past 10 years. One of the reasons discussed was that younger attending surgeons, without sufficient training, were often left alone to manage this complex situation when it happens during nights and weekends. From this perspective, the present paper appears reasonable but the ideal way to teach this complex surgery would be to start with elective repair of the ascending aorta, then composite graft replacement, and finally total aortic arch repair (TAR) under optimal supervision. The next step would logically be the same procedures in an emergency setting.

Of particular, as noted in the present paper is the fact that the attending surgeon who had performed 500 cardiac cases had a record of 100 TARs. This means that every fifth cardiosurgical procedure was an aortic arch repair. Such numbers are most probably neither representative for European nor for North American conditions.

It is surprising to read that some trainees had personal experience as operating surgeon with approximatively 50 cardiac cases, while others had operated 3 cases only before they were performing a total arch repair. I believe, this would be totally inconceivable in the majority of teaching institutions. I personally would not support a TAR as the third operative procedure for a younger trainee, and I do not see any reasonable advantage to bypass the usual steps of training.

In patients with a zone-2 TAR, the most difficult part to assist would be the anastomosis to the left subclavian artery. The authors avoid this step by performing an extra-anatomic bypass, leading the graft through the thorax and perform a more comfortable anastomosis outside. This is a debatable policy.

Finally, the duration of circulatory arrest was significantly longer in patients operated by trainees; while this is

(c) 2020. The Author(s).

This is an open access article published by Thieme under the terms of the Creative Commons Attribution-NonDerivative-NonCommercial-License, permitting copying and reproduction so long as the original work is given appropriate credit. Contents may not be used for commercial purposes, or adapted, remixed, transformed or built upon. (https://creativecommons.org/ licenses/by-nc-nd/4.0/) Georg Thieme Verlag KG, Rüdigerstraße 14, 70469 Stuttgart, Germany 
understandable, it is neither optimal nor acceptable for me. Since during zone-2 TAR, hypothermic arrest is needed only for the distal anastomosis, it would be helpful to know the duration of selective cerebral perfusion, since the latter would be more representative for the time needed for the completion of all anastomoses.

There is no doubt that training programs in cardiovascular and/or cardiothoracic surgery are currently under major pressure due to the overall decrease of cardiac surgery volume, increase in the complexity of the cases, and restricting hours for the younger generation. Nevertheless, dedicated and well-organized programs are increasingly required to prepare the next generation for the major future challenges in adult but also pediatric cardiac surgery.

In my opinion, it is still possible to manage teaching programs of increasing complexity, starting with thoracotomy, harvesting the left internal thoracic artery, institution and weaning from cardiopulmonary bypass, followed by achievement of specific steps of a full procedure.

In summary, while it appears reasonable that trainees do not have to perform their first aortic arch procedures alone in an emergency setting during off hours, a way "in between," for example, to teach TAR after an adequate number of more conventional procedures, might be preferable.

The group of the Mass General Hospital in Boston has published several highly interesting papers on that topic that I would warmly recommend for further reading. ${ }^{2-4}$

Thierry Carrel received 2015 the Da Vinci award of the European Association for cardiothoracic surgery as the best surgical teacher in Europe.

\section{References}

1 Kamiya H, Nakanishi S, Wakabayashi N, et al. Proximalized total arch replacement can be safely performed by trainee. Thorac Cardiovasc Surg 2020;68: In press

2 Tolis G Jr., Spencer PJ, Bloom JP, et al. Teaching operative cardiac surgery in the era of increasing patient complexity: can it still be done? J Thorac Cardiovasc Surg 2018;155(05): 2058-2065

3 Bloom JP, Heng E, Auchincloss HG, et al. Cardiac surgery trainees as "skin-to-skin" operating surgeons: midterm outcomes. Ann Thorac Surg 2019;108(01):262-267

4 Tolis G. Cardiac surgical operative training: a disincentivized necessity. Eur J Cardiothorac Surg 2019;55(02):173-178 